Jurnal Ilmu Sosial dan Pendidikan (JISIP)

Vol. 5 No. 3 Juli 2021

Terakreditasi Peringkat 5 (No. SK: 85/M/KPT/2020)

e-ISSN : 2656-6753, p-ISSN: 2598-9944

DOI: 10.36312/iisip.v5i3.2200/http://ejournal.mandalanursa.org/index.php/JISIP/index

\title{
Perancangan Sistem Informasi Pariwisata Berbasis Web Di Kabupaten Sukabumi
}

\author{
Nopita $^{1}$, Titin Pramiyati ${ }^{2}$ I Wayan Widi Pradnyana ${ }^{3}$ \\ ${ }^{123}$ Fakultas Ilmu Komputer,Universitas Pembangunan Nasional Veteran Jakarta ${ }^{1,2,3}$ \\ Email:nopita@upnvj.ac.id ${ }^{1}$, titin.pramiyati@upnvj.ac.id ${ }^{2}$ Wayan.widi@upnvj.ac.id $^{3}$
}

\begin{tabular}{|c|c|}
\hline Article Info & \multirow{5}{*}{$\begin{array}{l}\text { Abstract } \\
\text { Merujuk Pada Undang-undang Nomor } 22 \text { Tahun } 1999 \text {, yang mengatur } \\
\text { wewenang, dan kewajiban daerah otonom untuk mengatur dan } \\
\text { mengurus sendiri urusan pemerintahan dan kepentingan masyarakat } \\
\text { setempat. Hal ini diperuntungkan oleh dinas pariwisata sebagai } \\
\text { wewenang dalam mempromosikan pariwisata yang ada di } \\
\text { Kab.Sukabumi dalam bidang teknologi yang diharapkan dapat } \\
\text { mengurangi biaya dinas pariwisata dalam mempromosikan informasi } \\
\text { Pariwisata. Penelitian ini menggunakan metode waterfall dengan } \\
\text { tujuan untuk membuat Perancangan Sistem Informasi Pariwisata Di } \\
\text { Kabupaten Sukabumi Berbasis Web, sebagai media promosi berupa } \\
\text { informasi wisata unggulan, penginapan, rumah makan, kuliner } \\
\text { tradisional, seni tradisional, dan industri kreatif yang nantinya } \\
\text { pengunjung akan dialihkan menuju website link dekranasda., dan } \\
\text { penelitian ini menggunakan metode PIECES sebagai identifikasi } \\
\text { masalah. Hasil dari penelitian ini berupa aplikasi web yang sudah } \\
\text { dapat digunakan oleh pengunjung dan pihak dinas pariwisata. }\end{array}$} \\
\hline $\begin{array}{l}\text { Article Reseived: } 10 \text { July } 2021 \\
\text { Publication: } 20 \text { July } 2021\end{array}$ & \\
\hline \multirow{5}{*}{\begin{tabular}{l}
\multicolumn{2}{l}{ Kata Kunci: } \\
\multicolumn{1}{l}{ Sistem $\quad$ Informasi, } \\
Waterfall, PIECES, Dinas \\
Pariwisata, $\quad$ Kabupaten \\
Sukabumi.
\end{tabular}} & \\
\hline & \\
\hline & \\
\hline & This is an open access article under the Lisensi Creative Commons Atribusi-BerbagiSerupa 4.0 \\
\hline & (ब) (0) \\
\hline \multicolumn{2}{|l|}{ Corresponding Author: } \\
\hline \multicolumn{2}{|l|}{ Nopita } \\
\hline \multicolumn{2}{|c|}{ Fakultas Ilmu Komputer,Universitas Pembangunan Nasional Veteran Jakarta ${ }^{1,2,3}$} \\
\hline \multicolumn{2}{|c|}{ Email:nopita@upnvj.ac.id } \\
\hline
\end{tabular}

\section{PENDAHULUAN}

Menurut (Hendrianto, 2014), bahwa website adalah sekumpulan halaman web dan dapat digunakan untuk menghubungkan beberapa file yang saling terhubung. Dalam website ini ada sebuah halaman utama atau beranda yang pertama kali dilihat ketika pengguna mengakses web tersebut.

Membangun. sebuah.sistem informasi pariwisata berbasis web itu penting, sistem yang..dibangun ini wisatawan dapat memilih sendiri informasi penginapan yang dibutuhkan. Hal ini didasarkan pemikiran bahwa masing-masing wisatawan memiliki pertimbangan tersendiri..dalam menentukan tempat penginapannya (Soelistijadi, 2015).

Dari data Kementrian Pariwisata perkembangan wisatawan nasional dari tahun 2011-2016 menunjukan jumlah wisatawan nasional pada tahun 2011 jumlahnya 6,750,416 dengan tingkat pertumbuhan 8.26\%, tahun 2012 Jumlahnya 7,453,633 dengan tingkat pertumbuhan 10,42\% pada tahun ini perbedaan jumlah pada wisatawan nasional karena data estimasi/tidak ada survei outbound pada tahun 2012, tahun 2013 jumlahnya 8,024,876 tingkat pertumbuhan 7,66\%, pada tahun 2014 
jumlah wisatawan nasional 7,899,070 dengan tingkat pertumbuhan -1,57\%, 2015 Jumlah 7,908,534, tingkat pertumbuhan0,12\% dan hasil survei terakhir pada tahun 2016 jumlah wisatawan nasional 6,677,918 dengan tingkat persentase pertumbuhanya 1,97\%, data sementara ini di ambil dari 19 pintu keluar utama(Ardhiyani \& Mulyono, 2018).

Sukabumi sebagai salah satu daerah yang memiliki otonomi untuk mengembangkan teknologi, sangat memerlukan adanya perkembangan pariwisata yang didukung dengan teknologi informasi, hal ini disebabkan informasi wisata alam masih kurang dipromosikan, sehingga masyarakat dalam mendapatkan informasi wisata cukup lama, masyarakat harus datang ke kantor Dinas Pariwisata(Dispar Sukabumi, 2020).

Menurut Ardhiyani \& Mulyono (2018) menunjukan rancangan sistem informasi pariwisata berbasis web sanagat penting sebagai media promosi pada Kabupaten Tebo yang menggunakan bahasa pemrograman PHP dan database MySQL, yang dapat diimplementasikan sesuai dengan kebutuhan dalam pengolahan informasi supaya menjadi sebuah media promosi pariwisata yang ada di Kabupaten Tebo.

Pentingnya teknologi informasi untuk perkembangan pariwisata Sukabumi, dapat mempromosikan wisata yang tadinya tidak diketahui oleh masyarakat mengenai pariwisata apa saja yang ada di Sukabumi, menjadi tahu informasi apa saja yang ada, contohnya informasi wisata unggulan, seni tradisional, kuliner tradisional, rumah makan, penginapan dengan berbagai jenis, seperti hotel, homestay, dan villa, serta yang terpenting informasi industri kreatif sebagai ajang pengenalan produk lokal dan oleh-oleh khas Kab.Sukabumi yang tidak tercantum didalam brosur Dinas Pariwisata, dikarenakan sumber daya manusia (SDM) yang kurang mumpuni.

Merujuk Pada Undang-undang Nomor 22 Tahun 1999, yang mengatur wewenang, dan kewajiban daerah otonom untuk mengatur dan mengurus sendiri urusan pemerintahan dan kepentingan masyarakat setempat, dan untuk memperkenalkan pariwisata yang ada di Kab.Sukabumi memerlukan sebuah inovasi baru yang dapat memudahkan pengunjung dalam mencari informasi. Sehingga dibuatlah sebuah sistem informasi pariwisata berbasis web, sebagai penunjang kebutuhan informasi pariwisata dalam mempromosikan potensi daerah di Kab.Sukabumi. Penelitian ini bertujuan untuk merancang sistem informasi pariwisata berbasis website sebagai penopang eGovernment untuk peningkatan pendapatan dari sektor pariwisata untuk menyejahterakan masyarakat. Hal ini dimaksudkan agar informasi dapat disebarkan dengan ketersediaan jangkauan sebaran informasi yang lebih luas, informasi yang lebih lengkap, efektif dan efisien.

\section{KAJIAN PUSTAKA}

\subsection{Sistem Informasi}

Menurut (Mertayasa, \& Yambese, 2017), sistem informasi adalah sekumpulan data yang sudah tertata beserta cara penggunaanya yang melingkupi lebih jauh bukan hanya sekedar penyampaian. Istilah ini memiliki sesuatu yang ingin dicapai dengan memilih dan mengatur data untuk membuat daftar tata kelola untuk penggunaanya.

Sedangkan menurut (Satzinger et al.,2010), bahwa sistem informasi yaitu suatu kumpulan yang terdapat beberapa komponen berbeda dan berfungsi mengumpulkan, memproses, menyimpan, dan menyajikan ke dalam berbagai tugas dalam suatu bisnis. Berdasarkan pengertian diatas, bahwa sistem informasi ini bisa disimpulkan yaitu sekumpulan data yang saling berkolaborasi dan dirancang secara sistematis dan teratur. Kemudian diolah oleh komputer agar bermanfaat dan memiliki nilai guna.

\subsection{Website}

Menurut (Hendrianto, 2014), bahwa website adalah sekumpulan halaman web dan dapat digunakan untuk menghubungkan beberapa file yang saling terhubung. Dalam website ini ada sebuah halaman utama atau beranda yang pertama kali dilihat ketika pengguna mengakses web 
tersebut. Dari halaman utama, pengujung dapat mengakses fitur-fitur pada menu utama untuk berpindah pada menu lainya yang ada pada website tersebut.

\subsection{UML (Unified Modeling Language)}

Berdasarkan (Muslihudin, 2016), bahwa Unified Modelling Language (UML) merupakan requirement yang dapat menjelaskan dan menganalisis sebuah perancangan yang kompleks, setelah UML selesai dimodelkan dalam suatu diagram, maka akan lebih mudah dipahami dan dipelajari oleh pengguna.

\subsection{Metode Pengembangan Sistem Menggunakan Waterfall}

Berdasarkan (Pressman, dan Maxim 2015:29), bahwa model SDLC air terjun (waterfall) dapat disebut sebagai suatu model sekuensial linier (sequential linear) atau alur hidup klasik (classic life cycle), namun lebih dikenal dengan sebutan Waterfall. Ang didalamn aterdapat Software requirements analysis, Design,Coding, Testing, Maintenance.

\subsection{Blackbox Testing}

Yang biasa disebut dengan pengujian perilaku (behavior testing) merupakan suatu pengujian software yang memfokuskan pada input diaman pada umumnya mengerjakan tugas sesuai kebutuhan fungsi untuk program tersebut apakah sistem tersebut telah sesuai dengan perancangan yang dibangun. (Pressman, dan Maxim 2015)

\section{METODE PENELITIAN}

Metode penelitian ini adalah studi kasus dan pengembangan Program sistem informasi pariwisata kabupaten Sukabumi berbasi WEB yang digambarkan pada gambae berikut:

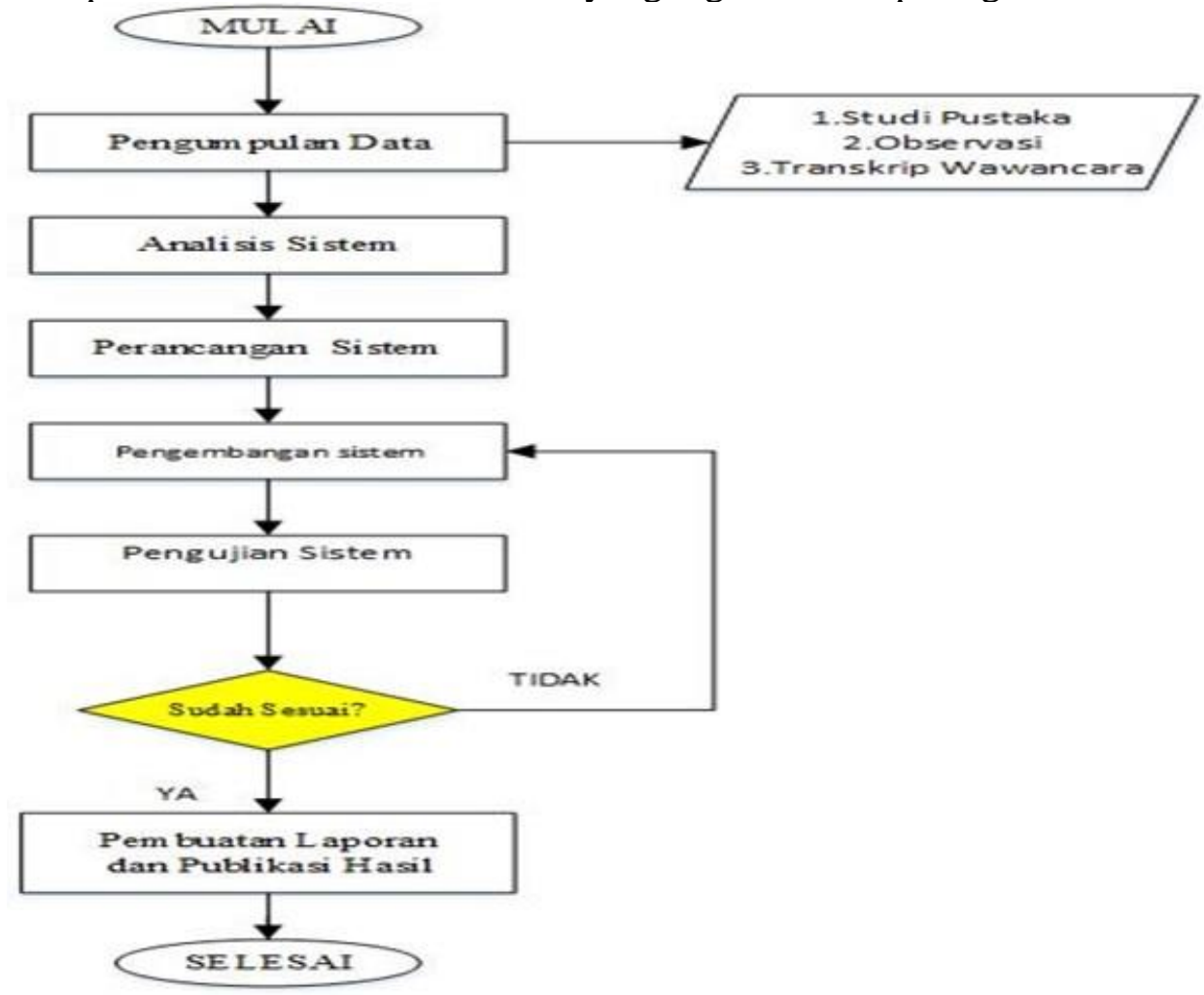

Gambar 1 Alur Penelitian

Proses penelitian ini melewati beberapa tahap sebagai berikut:

\subsection{Pengumpulan Data}

tahap ini pengumpulan data yang dibutuhkan untuk melakukan pengembangan sistem yang akan ditempuh dengan tiga cara, yaitu Studi Pustaka dengan mempelajari buku, jurnal dan referensi 
yang sesuai dengan penelitian yang akan dilakukan, Observasi dan Wawancara untukmengumpulkan data yang dibutuhkan dalam pembuatan sistem.

\subsection{Analisis Sistem}

Pada tahap ini dilakukan identifikasi masalah sistem yang sedang berjalan, dan diharapkan sebuah penelitian yang mendapati sebuah hambatan dan permasalahan yang sedang terjadi pada dinas pariwisata, dan dapat mencari jalan keluar dari setiap permasalahan yang ada.

\subsection{Perancangan Sistem}

Setelah proses analisis sistem selesai, maka dilakukan tahap perancangan sistem yang bertujuan untuk memudahkan kinerja serta memberikan gambaran umum mengenai mekanisme yang sesuai untuk mendesain sebuah sistem informasi pariwisata di Kab.Sukabumi. yang bertujuan untuk memberikan solusi dan penyelesaian masalah dengan membuat suatu desain sistem yang baku dan konkrit untuk memberikan informasi yang lebih akurat.

\subsection{Pengembangan Sistem}

Dalam perancangan sistem ini akan menggunakan pendekatan SDLC (System Development Life Circle) yang didalamnya terdiri dari Analisis Kebutuhan, dimana perangkat lunak yang akan dibuat dan dirancang, meliputi analisis input, analisis proses dan analisis kebutuhan, Desain, pada tahap ini, dilakukan perancangan perangkat lunak yang dimaksudkan untuk memberi gambaran berupa rancangan UML yang sudah dijelaskan pada proses perancangan sistem guna membantu dalam menjelaskan kebutuhan dan arsitektur perangkat lunak secara lengkap, dan Pemgrograman, Tahap ini, merupakan proses coding atau pembuatan perangkat lunak, dengan menggunakan bahasa pemrograman PHP dengan framework Codeigniter dan basis data MySQL

\subsection{Pengujian Sistem,}

Pada pengujian sistem ini merupakan akhir dari proses tahapan yang telah dibuat diatas tadi dengan menggunakan Blackbox Testing. Untuk mengetahui apakah perangkatlunak yang dibuat telah sesuai dengan kebutuhan desain, apakah masih.

\section{HASIL DAN PEMBAHASAN}

\subsection{Use Case Diagram Sistem Berjalan}

Berikut merupakan use case diagram sistem berjalan yang masih menggunakkan cara konvesional dalam memberikan informasi pariwisata di kabupaten sukabumi pada wisatawan.

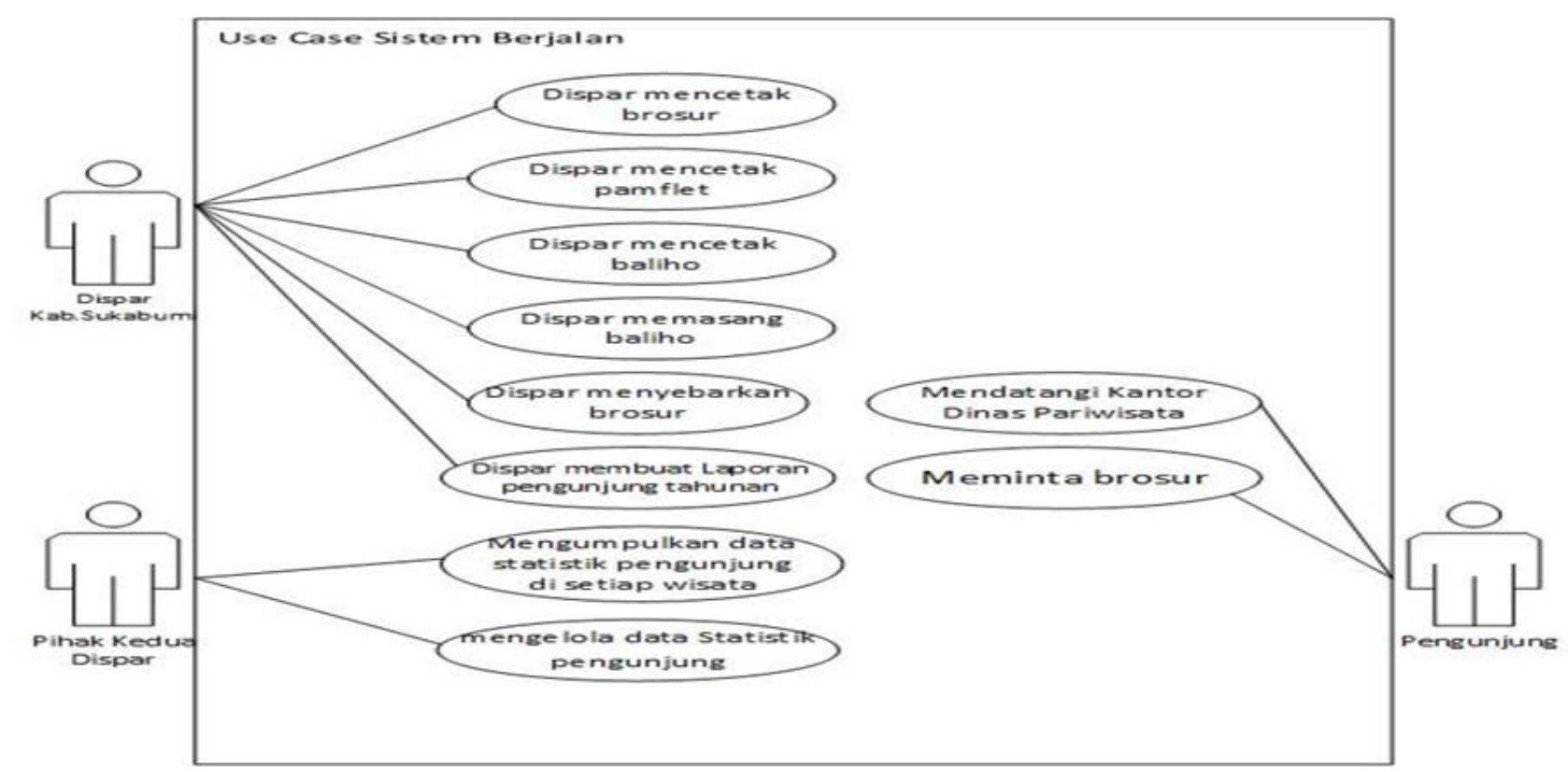


Gambar. 2. Use Case Diagram Sistem Berjalan

\subsection{Identifikasi Masalah dengan Metode PIECES}

Dari use case diagram sistem berjalan yang sudah dijelaskan diatas, maka dilakukan analisis menggunakan Metode PIECES, dengan hasil analisis ang didapat sebagai berikut:

Performance, proses kinerja dari sistem yang berjalan belum dirasa maksimal, dikarenakan masih banyaknya kinerja yang dilakukan secara konvensional, seperti halnya penyebaran informasi yang harus melakukan pencetakan brosur, pamflet, dan baliho, dikarenakan setiap tahunya tema pariwisata kabupaten sukabumi selalu berbeda, sehingga kinerja ini menjadi banyak menguras banyak biaya, waktu dan proses promosi.

Information, kualitas informasi yang dihasilkan dari sistem konvesional masih dikatakan kurang maksimal, karena proses informasi pariwisata tidak dapat diterima langsung oleh pengunjung dan tidak dapat diketahui oleh banyak orang, seperti informasi wisat a unggulan, dan informasi lainya, sehingga banyak pengunjung yang masih menggunakan cara konvensional untuk mendapatkan informasi resmi dari dinas pariwisata, dengan mendatangi kantor dinas pariwisata, kurangnya informasi dari pihak yang terkait menyebabkan informasi simpang siur mengenai wisata yang ada di kabupaten sukabumi.

Economic, penggunaan biaya dari penyebaran informasi ang maish menggunakan konvesional ini pihak dinas harus memasang baliho di tempat strategis, sehingga harus mengeluarkan biaya ekstra dalam proses pencetakan, pemasangan, dan pembayaran pajak yang dimana semua itu menggunakan anggaran dana daerah kabupaten Sukabumi yang menimbulkan pemborosan biaya dari tahun -ketahun yang terus berulang.

Control, Dalam proses monitoring terjadi kinerja yang dirasa tidak dapat dikatakan optimal, karena dispar hanya memasang baliho di tempat strategis, yang mana belum tentu menarik minat banyak wisatawan, sehingga monitoring ini hanya dilakukan dalam satu tempat saja, dan setiap tahunya harus mengganti baliho tersebut dengan tema yang berbeda, sehingga hal ini tidak dapat melakukan monitoring yang maksimal, dan tidak dapat menghasilkan informasi yang uptodate pada momen penting tertentu.

Efficiency, Proses penyebaran informasi ini dapat diharapan pihak dinas hanya perlu mengurangi pembuatan brosur, pamflet, dan baliho, sehingga tidak menimbulkan biaya yang tinggi setiap tahunya, dan anggaran pariwisata dapat dialokasikan kepada kepentingan sarana dan prasarana untuk wisata lain.

Service, sistem pelayanan yang diberikan oleh pihak dispar masih terbatas. Jika hal ini terus berlanjut makan proses layanan yang disediakan dispar tidak akan di lirik lagi oleh pengunjung, dan pelayanan ini akan dirasa tidak memuas kan bagi pengunjung.

\subsection{Use case diagram sistem usulan}

Berikut merupakan use case diagram sistem usulan dalam merancang sistem informasi Pariwisata Di Kabupaten Sukabumi. 


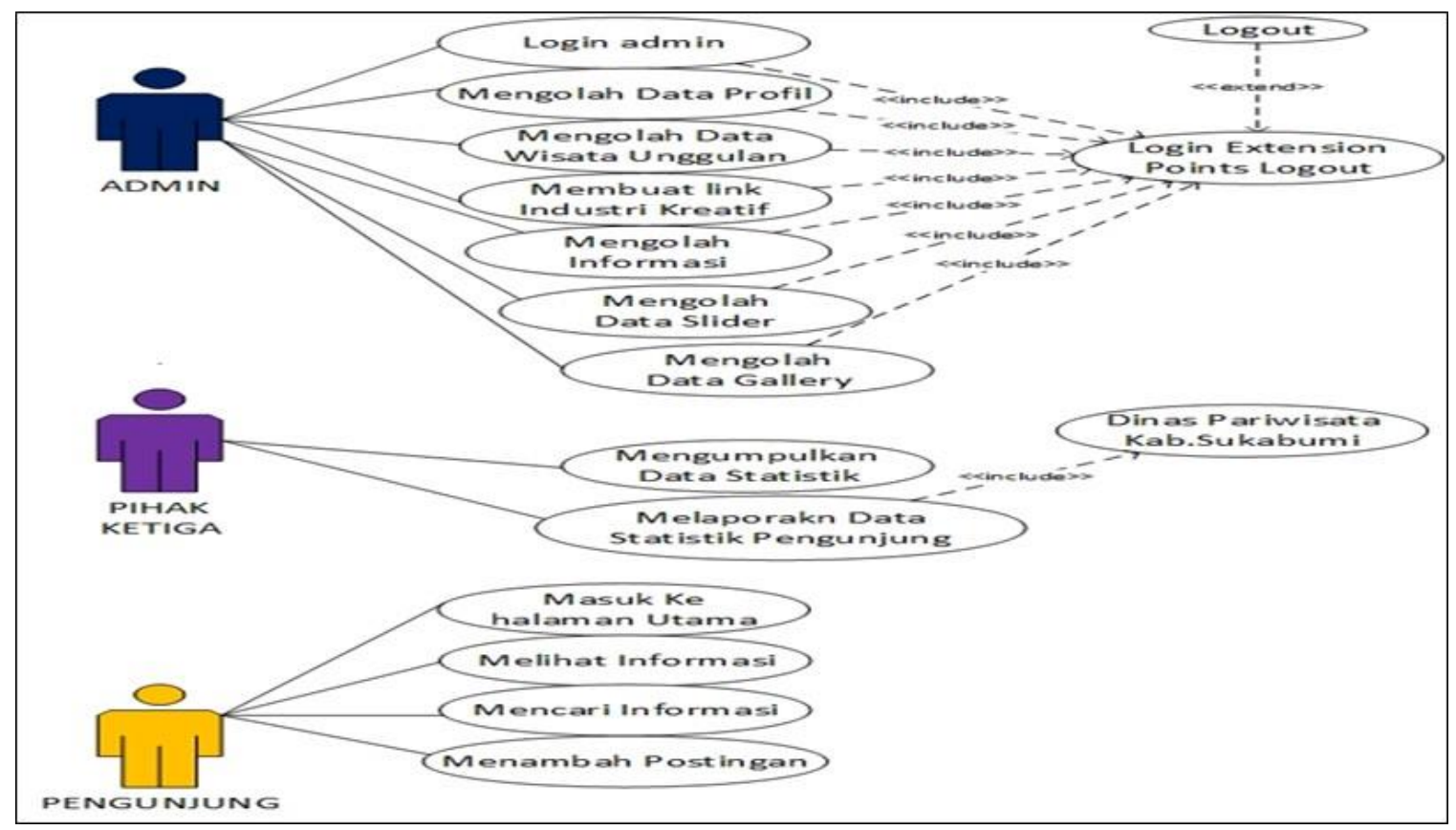

Gambar 3 Diagram Usulan

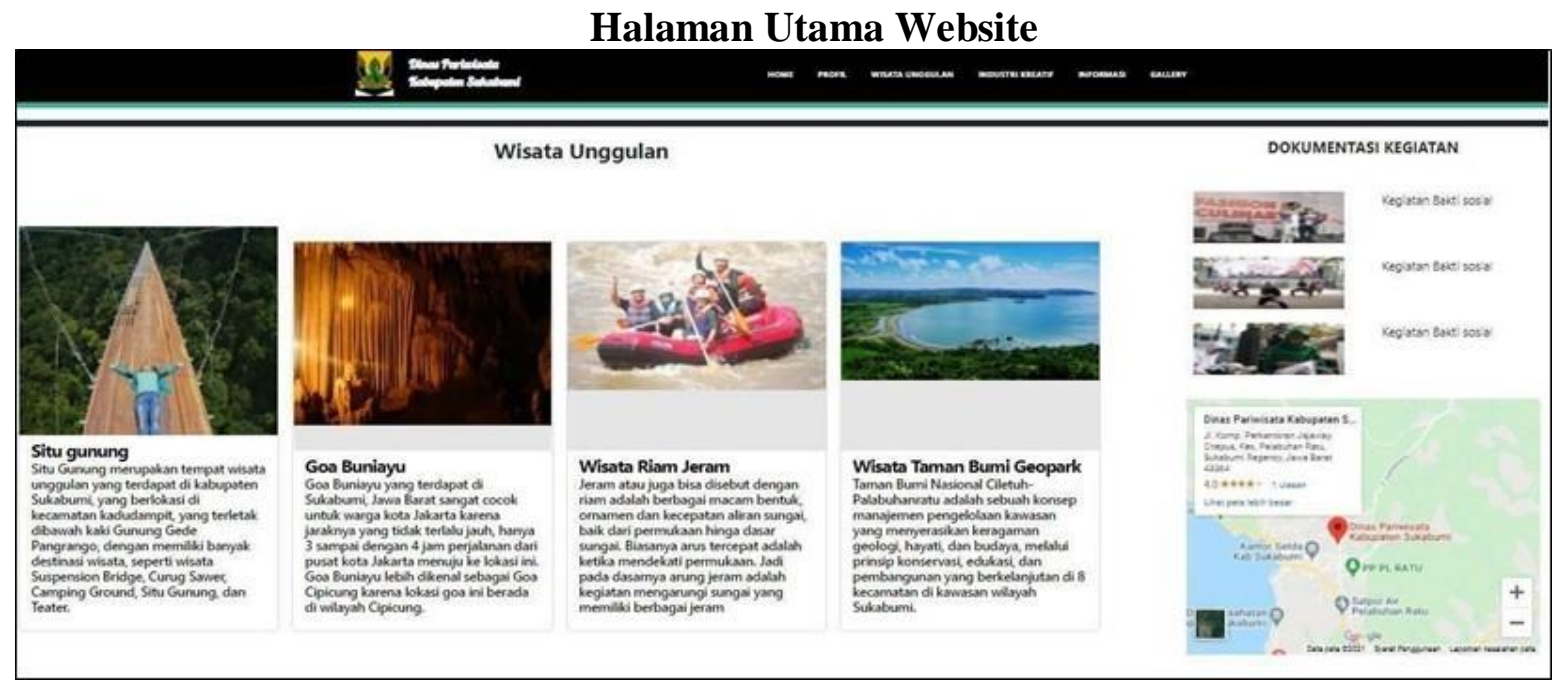

Gambar 4. Tampilan Halaman Utama Wisata Unggulan

Halaman Posting Pengunjung Website

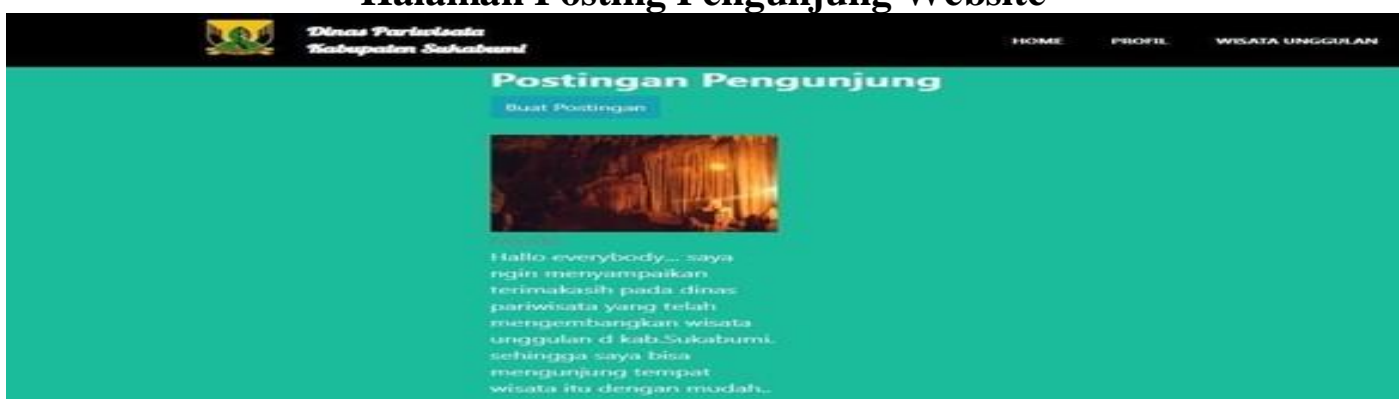

Gambar 5. Tampilan Postingan Pengunjung 


\section{Halaman Login Admin}

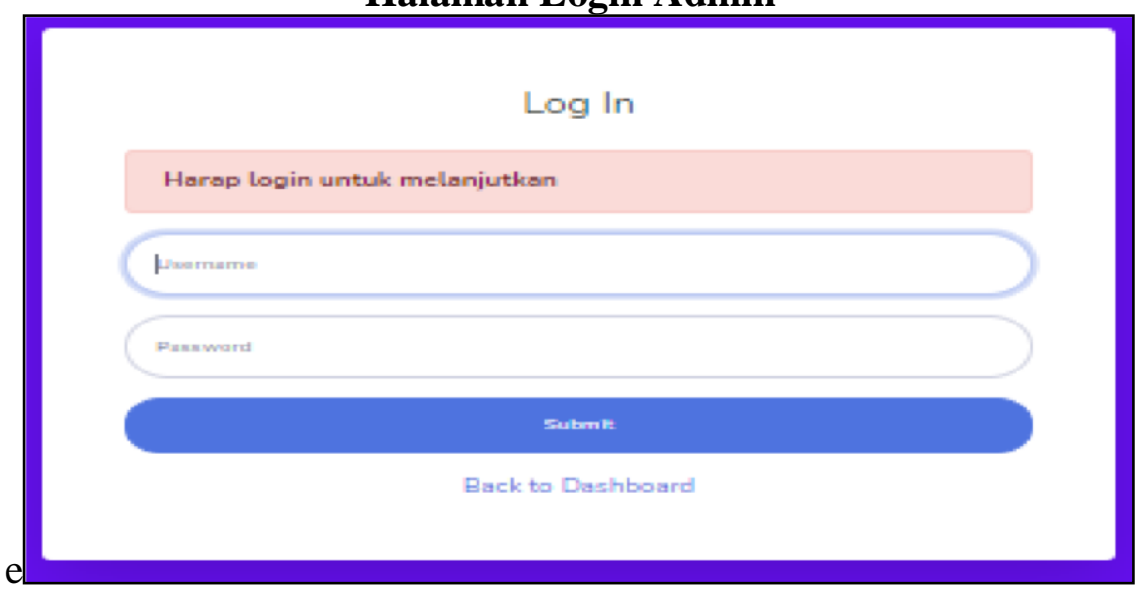

Gambar 6. Tampilan Login Admin

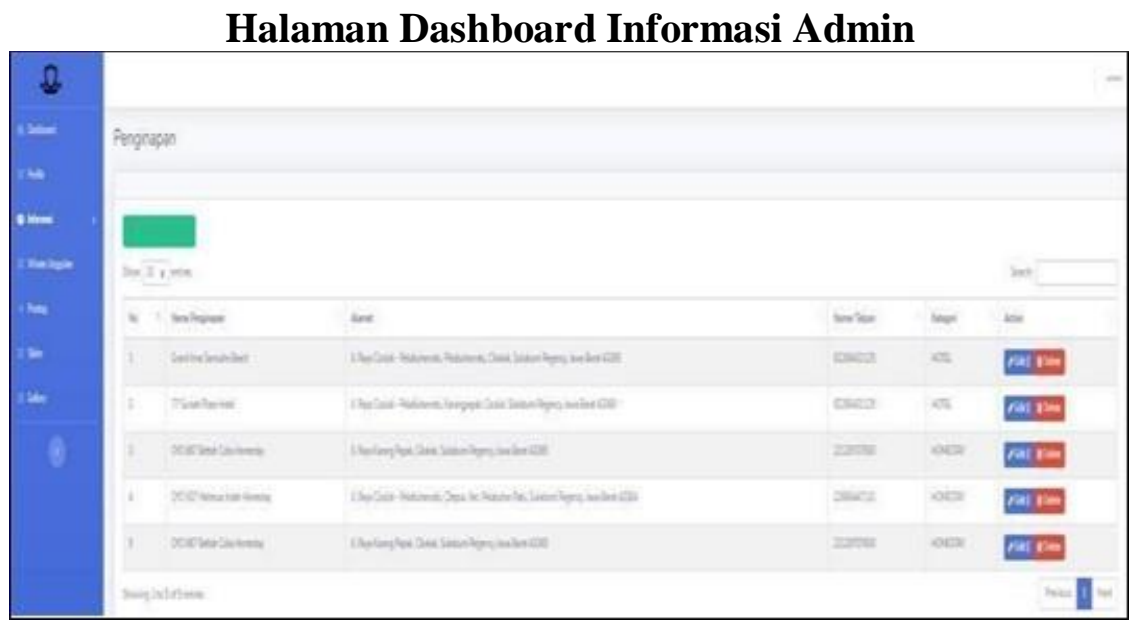

Gambar 7. Tampilan Penginapan Admin

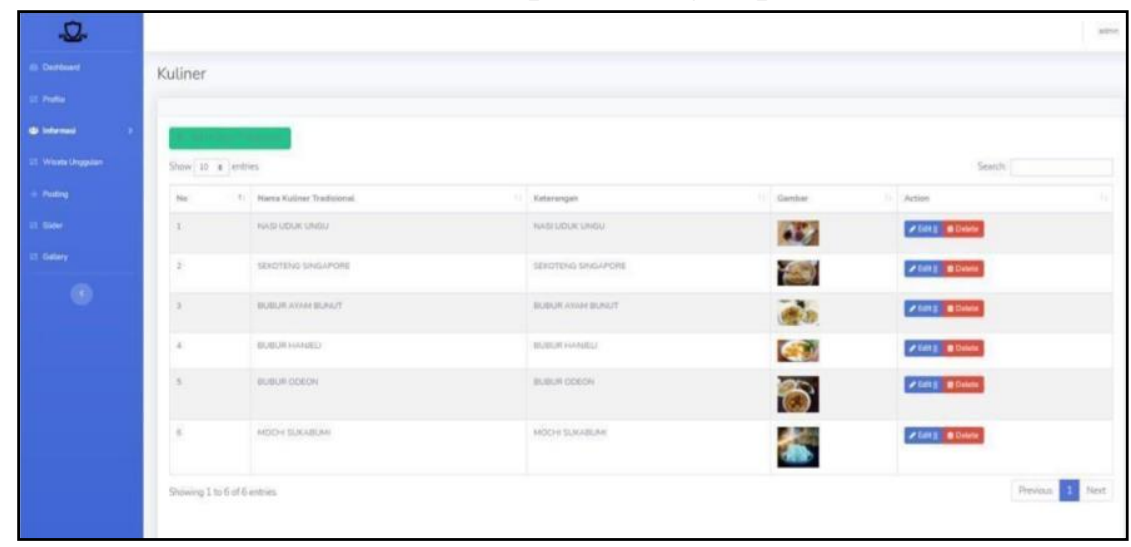

Gambar 8. Tampilan Kuliner Admin 


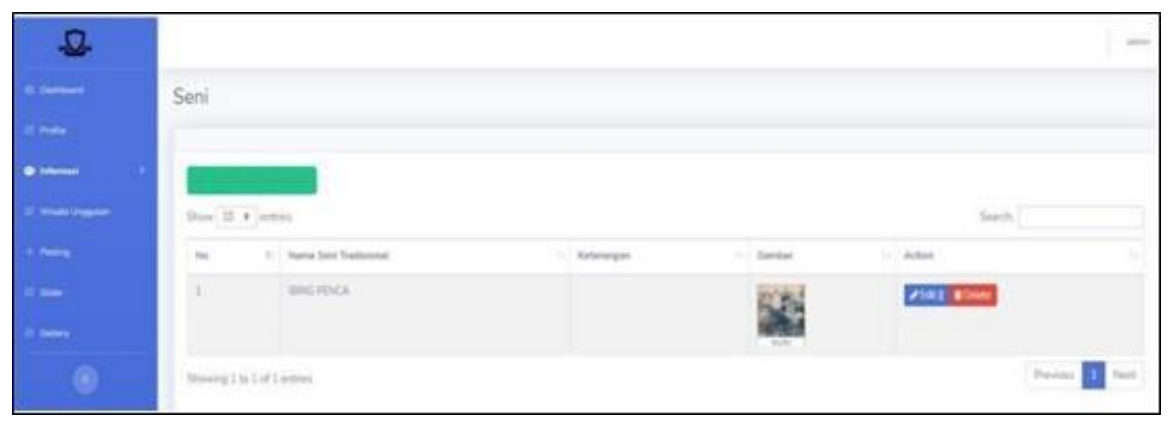

Gambar 9. Tampilan Seni Tradisional Admin

\subsection{Pengujian Sistem: Blackbox Testing}

Berikut merupakan pengujian sistem dengan menggunakan blackbox testing.

Tabel 1. pengujian sistem dengan menggunakan blackbox testing.

\begin{tabular}{|c|c|c|c|}
\hline No & Nama Kegiatan/ Test & Hasil yang Diharapkan & Hasil Test \\
\hline 1. & Masuk menu profile, klik tombol reset & Sistem berhasil reset dataprofil & Sesuai Harapan \\
\hline 2. & $\begin{array}{l}\text { Masuk menu profile, klik tombol } \\
\text { update }\end{array}$ & Sistem berhasil update data profil & Sesuai Harapan \\
\hline 3. & $\begin{array}{l}\text { Masuk menu informasi penginapan, } \\
\text { klik add wisatamasukkan data }\end{array}$ & $\begin{array}{l}\text { Sistem berhasil menambahkan } \\
\text { file penginapan }\end{array}$ & Sesuai Harapan \\
\hline 4. & $\begin{array}{l}\text { Masuk menu informasi penginapan,Klik } \\
\text { tombol edit }\end{array}$ & $\begin{array}{l}\text { Sistem berhasil mengeditdata } \\
\text { penginapan }\end{array}$ & Sesuai Harapan \\
\hline 5. & $\begin{array}{l}\text { Masuk menu informasi penginapanklik } \\
\text { tombol delete }\end{array}$ & $\begin{array}{l}\text { Sistem berhasil delete fil e yang ada } \\
\text { pada data penginapan. }\end{array}$ & Sesuai Harapan \\
\hline 6. & $\begin{array}{l}\text { Masuk menu informasi rumah makan } \\
\text { add rumah makan }\end{array}$ & $\begin{array}{l}\text { Sistem berhasil menambah } \\
\text { data rumah makan }\end{array}$ & Sesuai Harapan \\
\hline 7. & $\begin{array}{l}\text { Masuk menu informasi rumah makan } \\
\text { Klik tombol edit }\end{array}$ & $\begin{array}{l}\text { Sistem berhasil mengeditdata rumah } \\
\text { makan }\end{array}$ & Sesuai Harapan \\
\hline 8. & $\begin{array}{l}\text { Masuk menu informasi rumah makan, } \\
\text { klik tombol delete }\end{array}$ & $\begin{array}{l}\text { Sistem berhasil delete file yang ada } \\
\text { pada data rumah makan }\end{array}$ & Sesuai Harapan \\
\hline 9. & $\begin{array}{l}\text { Masuk menu informasi seni } \\
\text { tradisional, add seni }\end{array}$ & $\begin{array}{l}\text { Sistem berhasil menambah } \\
\text { data seni tradisional }\end{array}$ & Sesuai Harapan \\
\hline 10. & $\begin{array}{l}\text { Masuk menu informasi senitradisional } \\
\text { Klik tombol edit }\end{array}$ & $\begin{array}{l}\text { Sistem berhasil mengeditdata } \\
\text { seni tradisional }\end{array}$ & Sesuai Harapan \\
\hline 11. & $\begin{array}{|lc|}\begin{array}{l}\text { Masuk menu informasi } \\
\text { tradisional, klik tombol delete }\end{array} & \\
\end{array}$ & $\begin{array}{l}\text { Sistem berhasil delete fil e yang ada } \\
\text { pada data seni tradisional }\end{array}$ & Sesuai Harapan \\
\hline 12. & $\begin{array}{l}\text { Masuk menu informasi kuliner, add } \\
\text { kuliner }\end{array}$ & $\begin{array}{l}\text { Sistem berhasil menambah } \\
\text { datakuliner }\end{array}$ & Sesuai Harapan \\
\hline 13. & $\begin{array}{l}\text { Masuk menu informasi kuliner, Klik } \\
\text { tombol edit }\end{array}$ & Sistem berhasil mengeditdata kuliner & Sesuai Harapan \\
\hline 14. & $\begin{array}{l}\text { Masuk menu informasi kuliner, klik } \\
\text { tombol delete }\end{array}$ & $\begin{array}{l}\text { Sistem berhasil delete file yang ada } \\
\text { pada data kuliner }\end{array}$ & Sesuai Harapan \\
\hline 15. & $\begin{array}{l}\text { Masuk menu informasi } \\
\text { Statistik pengunjung, klik add }\end{array}$ & $\begin{array}{l}\text { Sistem berhasil menambah } \\
\text { data Statistik pengunjung }\end{array}$ & Sesuai Harapan \\
\hline 16. & $\begin{array}{l}\text { Masuk menu informasi } \\
\text { Statistik pengunjung, Kliktombol edit }\end{array}$ & \begin{tabular}{|l} 
Sistem berhasil mengedit data \\
Statistik \\
pengunjung
\end{tabular} & Sesuai Harapan \\
\hline
\end{tabular}




\begin{tabular}{|l|l|l|l|}
\hline 17. & $\begin{array}{l}\text { Masuk menu informasi Statistik } \\
\text { pengunjung klik tombol delete }\end{array}$ & $\begin{array}{l}\text { Sistem berhasil delete file yang ada } \\
\text { pada data Statistik pengunjung }\end{array}$ & Sesuai Harapan \\
\hline 18. & $\begin{array}{l}\text { Masuk menu wisata unggulan,klik add } \\
\text { wisata }\end{array}$ & $\begin{array}{l}\text { Sistem berhasil menambah data } \\
\text { wisata unggulan }\end{array}$ & Sesuai Harapan \\
\hline 19. & $\begin{array}{l}\text { Masuk menu wisata unggulan,Klik } \\
\text { tombol edit, }\end{array}$ & $\begin{array}{l}\text { Sistem berhasil mengeditdata wisata } \\
\text { unggulan }\end{array}$ & Sesuai Harapan \\
\hline 20. & $\begin{array}{l}\text { Masuk menu wisata unggulan,klik } \\
\text { tombol delete }\end{array}$ & $\begin{array}{l}\text { Sistem berhasil delete file yang ada } \\
\text { pada data wisataunggulan }\end{array}$ & Sesuai Harapan \\
\hline 21. & $\begin{array}{l}\text { Masuk menu posting, klik tombol } \\
\text { delete }\end{array}$ & $\begin{array}{l}\text { Sistem berhasil delete postingan } \\
\text { pengunjung. }\end{array}$ & Sesuai Harapan \\
\hline 22. & $\begin{array}{l}\text { Masuk menu Slider, klik addslider. } \\
\text { Sistem berhasil menambah data } \\
\text { slider }\end{array}$ & Sesuai Harapan \\
\hline 23. & $\begin{array}{l}\text { Masuk menu Slider, klik tombol } \\
\text { delete }\end{array}$ & Sistem berhasil delete dataslider & Sesuai Harapan \\
\hline
\end{tabular}

Pengembangan sistem informasi pasiwisata berbasis WEB di Kabupaten Sukabumi merupakan langkah bagus dalam menunjang dan meningkatkan sektor wisata Sukabumi, dengan meningkatnya sektor wisata maka akan mendongkrak pendapatan daerah dan menjadi sumber pendapatan bagi sektor usaha UMKM bagi masyarakat Sukabumi.

Penelitian serupa juga dilakukan oleh Menurut Kwa \& Arbil (2017) dengan adanya website ini, maka dapat membantu kantor Dinas Pariwisata dan Ekonomi Kreatif dalam memberikan informasi pariwisata. Website ini memiliki beberapa fitur, antara lain forum atau mini chat untuk saling bertukar informasi, halaman registrasi untuk para pengunjung untuk mendaftar menjadi kontributor agar mendapat hak akses memasukan informasi mengenai pariwisata, forum, dan foto.

Penelitian yang dilakukan oleh Prayudi, Umar, \& Yudhana (2018) menyatakan sistem dirancang agar Dinas Kebudayaan adan Pariwisata Kabupaten Dompu dapat mengelola informasi-informasi pariwisata secara efektif dan efisien sehingga memberikan informasi terbaru tentang tempat-tempat wisata di Kabupaten Dompu kepada wisatawan.

\section{KESIMPULAN}

Dari Hasil analisis selama penelitian didapat sebuah kesimpulan yang diambil berikut ini penjelasanya.

1. Bahwa perancangan sistem informasi website pariwisata ini sudah dapat memenuhi kebutuhan informasi bagi masyarakat kabupaten Sukabumi, hal ini dapat dilihat dengan adanya informasi wisata unggulan beserta informasi pendukung lainya seperti industri kreatif, informasi penginapan, rumah makan, kuliner tradisional, dan seni tradisional.

2. Adanya sistem informasi berbasis website ini, dapat menyebarkan informasi pariwisata lebih luas, efisien, dan efektif.

3. Sistem informasi berbasis website ini dapat mengurangi biaya pengeluaran Dinas Pariwisata dalam melakukan promosi pariwisata di Kabupaten Sukabumi

\section{SARAN}

Saran yang dapat disampaikan oleh penulis adalah sebagai berikut.

1. Adanya keterbatasan sumber data dan waktu, penelitian ini diharapkan dapat dikembangkan dengan menambah fitur informasi lainya untuk kebutuhan kedepanya.

2. Statistik pengunjung dapat dijadikan metodologi penelitian mengenai potensi wisata unggulan baru. 
3. Sistem Informasi ini diharapkan dapat menjadi sistem yang memiliki video 360 untuk objek wisata unggulan

\section{DAFTAR PUSTAKA}

Ardhiyani, R. P., \& Mulyono, H. (2018). Analisis Dan Perancangan Sistem Informasi Pariwisata Berbasis Web Sebagai Media Promosi Pada Kabupaten Tebo Tebo. Jurnal Manajemen Sistem Informasi, 3(1), 952-972.

Dispar Sukabumi. (2020). Pariwisata Sukabumi.

Kwa, L., \& Arbil, R. (2017). Sistem Informasi Pariwisata Provinsi Papua Berbasis Web. Seminar Nasional Aptikom (Semnastikom),.

Prayudi, A., Umar, U., \& Yudhana, A. (2018). Perancangan Sistem Informasi Pariwisata Di Kabupaten Dompu Berbasis Website. Seminar Nasional Informatika 2018, 2018(Semnasif), 26-30.

Hendrianto, D., E. (2014) 'Pembuatan sis tem informasi perpustakaan berbasis website pada sekolah mengeha pertama negeri 1 donorojo kabupaten pacitan’, IJNS: Indonesian Jurnal on Networking and Security, Vol. 3, No

Mertayasa, D. M., \& Yambese, A. R. 2017. Sistem Informasi Pariwisata Pantai Berbasis Web Pada Dinas Pariwisata dan Ekonomi Kreatif Kabupaten Banggai Kepulauan. Elektronik Sistem Informasi dan Komputer, 3(1), 1-13.o.

Muslihudin, M., \& O. (2016) Analisis dan Perancangan Sistem Informasi Menggunakan Model Terstruktur dan UML. Yogyakarta: Andi

Pressman, Roger S., Maxim, B. R. (2015) Software Engineering A Practitioner's. 8th edn. New York: McGraw-Hill

Soelistijadi, R. 2015. Sistem Informasi Pariwisata Berbasis Web : Studi Kasus Fasilitas Penginapan Di Wilayah Propinsi Yogyakarta, 7(1), 59-67. 